\title{
Optical attributes influence on mechanical properties of laser cutted PMMA
}

\author{
Jozef Meško ${ }^{1}$, Rastislav Nigrovič ${ }^{1, *}$ \\ ${ }^{1}$ UNIZA, Faculty of Mechanical Engineering, Department of Technological Engineering, Univerzitna \\ 8215/1, 01026 Žilina, Slovakia
}

\begin{abstract}
The article describes and characterizes the technology and principle of laser cutting PMMA material. Experimental samples with thickness $t=3 \mathrm{~mm}$ of PMMA were made with a constant optimized technological parameters of laser cutting. In the experimental part are compared values of hardness of cutted surface, tensile strength of different colour variations and impact on selected mechanical properties by change of technological procedures of selected material processing tempering of plastics.
\end{abstract}

Keywords: PMMA, Laser cutting, Mechanical properties, Optical attributes of PMMA

\section{Introduction}

The principle of the laser cutting of metallic or non-metallic materials is based on the action of a focused laser beam on the material being cut. When cutting materials in technical practice, the surface is impacted by a focused circular beam of a diameter 0.1 to $0.4 \mathrm{~mm}$, depending on the device construction and the thickness of the material to be cut. The laser beam of the above parameters, impacting the material being cut, will cause its rapid heating up. The material being cut is heated in milliseconds up to the melting or to the evaporation temperature.

When the laser beam hits the material being cut, there occurs an interaction between the material being cut and the laser beam. The subsequent processes, which take place during the cutting of the material, and the effect on the material properties following the focused beam impact, mainly depend on the chemical composition of the material being cut and on the quality of its surface, as well.

In thermal cutting of metallic or non-metallic materials by a laser, it is always necessary first to create a hole in the processed material, from which the cutting would continue. Making the hole is based on the laser drilling principle and has slightly different characteristics of the course than that of the actual cutting. The impacting laser beam transmits the kinetic energy of the material photons, which is converted into heat that melts and partially evaporates the material being heated.

\footnotetext{
*Corresponding author: rastislav.nigrovic@fstroj.uniza.sk

Reviewers: Andrej Czán, Ján Vavro
} 
The surroundings of the laser beam inflammation site (in the material being cut) contain gases that become ionized instantaneously as the beam hits the material and change to plasma.

The material being cut sublimates into a gaseous state, and is blown away from the material to the environment by the action of an assist gas under a relatively high pressure. The part of the material, which is not converted into a gaseous state, is blown by the flowing assist gas in the liquid form. The above-mentioned process causes formation of a pit in the material being cut, and the laser beam can penetrate continuously deeper, which results in depth melting of the material (Fig. 1).

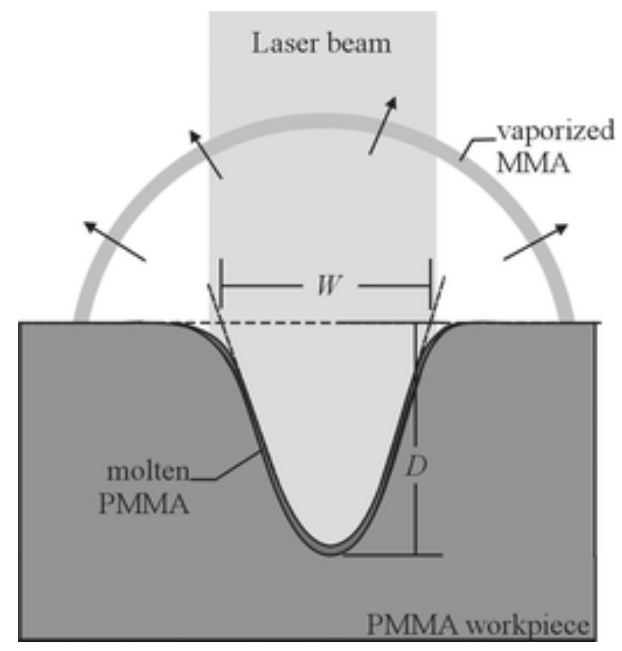

Fig. 1. The principle of PMMA laser cutting

$\mathrm{CO}_{2}$ lasers are particularly well suited to the cutting of PMMA. Applications of thermoplastic PMMA have grown considerably in many cases, for example, lenses, light pipes, outdoor signs, light covers, bathroom fittings, skylights, meter covers, baths and toys (Fig. 2) [1-6].

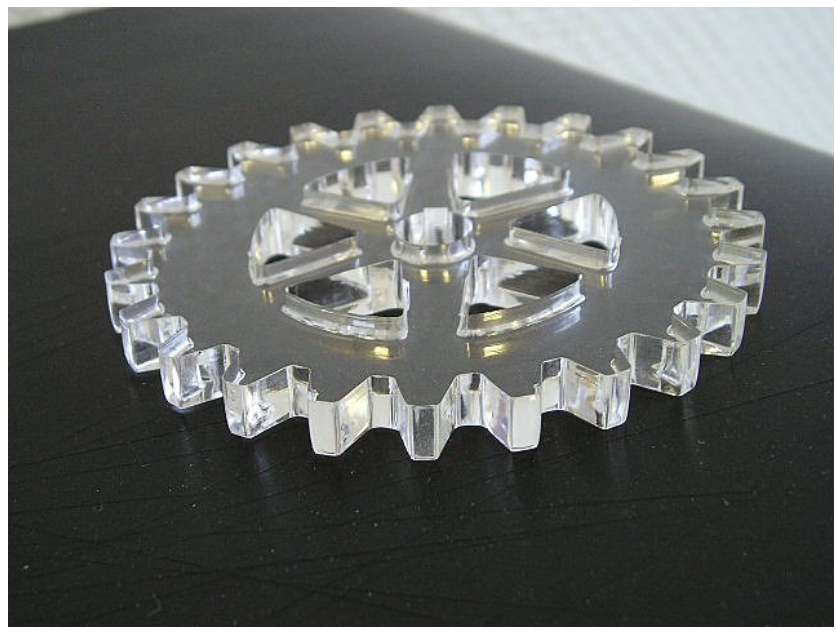

Fig. 2. A demonstration of a laser workpiece from PMMA 


\section{Experimental conditions}

\subsection{Experimental material}

General Poly(methacrylates) are polymers of the esters of methacrylic acids. The most commonly used among them is poly(methyl metacrylate) (PMMA). Poly(methyl metacrylate) or poly(methyl 2 - methylpropenoate) is the polymer of methyl methacrylate, with chemical formula $\mathrm{C} 5 \mathrm{H} 8 \mathrm{O} 2$. I tis a clear colourless polymer available on the market in both pellet and sheet form under the names Plexiglas, Acrylite, Perspex, Plazcryl, Acylplast, Altuglas, Lucite etc. I tis commonly called acrylic glass or simply acrylic. [5]

Table 1. Selected properties of PMMA

\begin{tabular}{|c|c|}
\hline Density & $1,15-1,19\left[\mathrm{~g} . \mathrm{cm}^{-3}\right]$ \\
\hline Water absorption & $0,3-2[\%]$ \\
\hline Hardness, Rockwell M & $63-97$ \\
\hline Tensile Strength, Ultimate & $47-49[\mathrm{MPa}]$ \\
\hline Tensile Modulus & $2.2-3.8[\mathrm{MPa}]$ \\
\hline Specific Heat Capacity & $\left.1.46-1.47 \mathrm{~J} / \mathrm{g} .{ }^{\circ} \mathrm{C}\right]$ \\
\hline Thermal Conductivity & $0.19-0.24[\mathrm{~W} / \mathrm{m} . \mathrm{K}]$ \\
\hline Maximum Service Temperature, Air & $41-103\left[{ }^{\circ} \mathrm{C}\right]$ \\
\hline Melting Point & $130\left[{ }^{\circ} \mathrm{C}\right]$ \\
\hline Vicat Softening Point & $47-117\left[{ }^{\circ} \mathrm{C}\right]$ \\
\hline
\end{tabular}

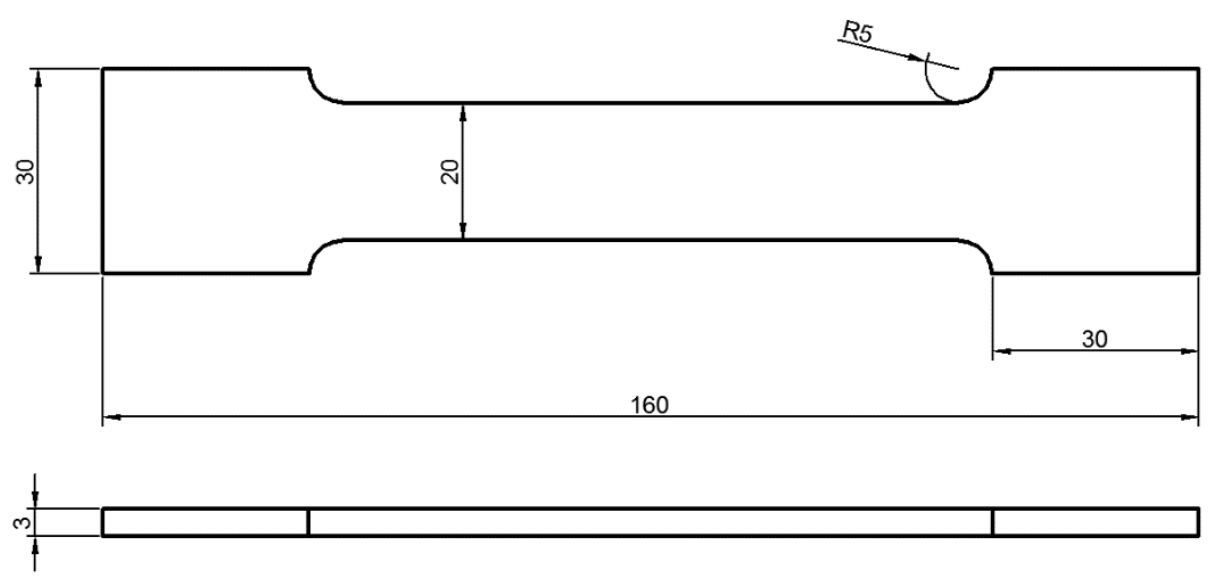

Fig. 3. Sketch of comparative samples for tensile test 


\subsection{Experimental machine}

\section{Laser cutting machine - XL 1200}

With the laser cutting and engraving machine XL-1200 for acrylics eurolaser offers the possibility to process extremely broad materials on a comparatively small system. The processing area is $2270 \mathrm{~mm} \times 1230 \mathrm{~mm}$. With the optional camera recognition system which is also available for other systems the production flow can be automated, leading to an increased economy of the laser processing [7].

Cutting parameters :

- power - $100[\mathrm{~W}]$

- cutting speed $-13\left[\mathrm{~mm} . \mathrm{s}^{-1}\right]$

All experimental samples were tempered for 5 hours at $80^{\circ} \mathrm{C}$ before to mechanical tests, resulting in improved mechanical properties, due to higher confidence in measurement results and to avoid high brittleness of the measured samples.

\section{Experimental part}

The experiment should demonstrated the interaction between the optical properties of PMMA (Table 1.) material and mechanical properties after laser cutting. The material was made with constant conditions, but with other colour variation and light transmission (Fig. 6.). The laser for cutting of material uses a concentrated photon beam. The optical properties of the cut material greatly affecting the quality of the cut and the properties of the cut material. For the experiment were selected four colour variations of PMMA, with different light absorption (Fig. 4).

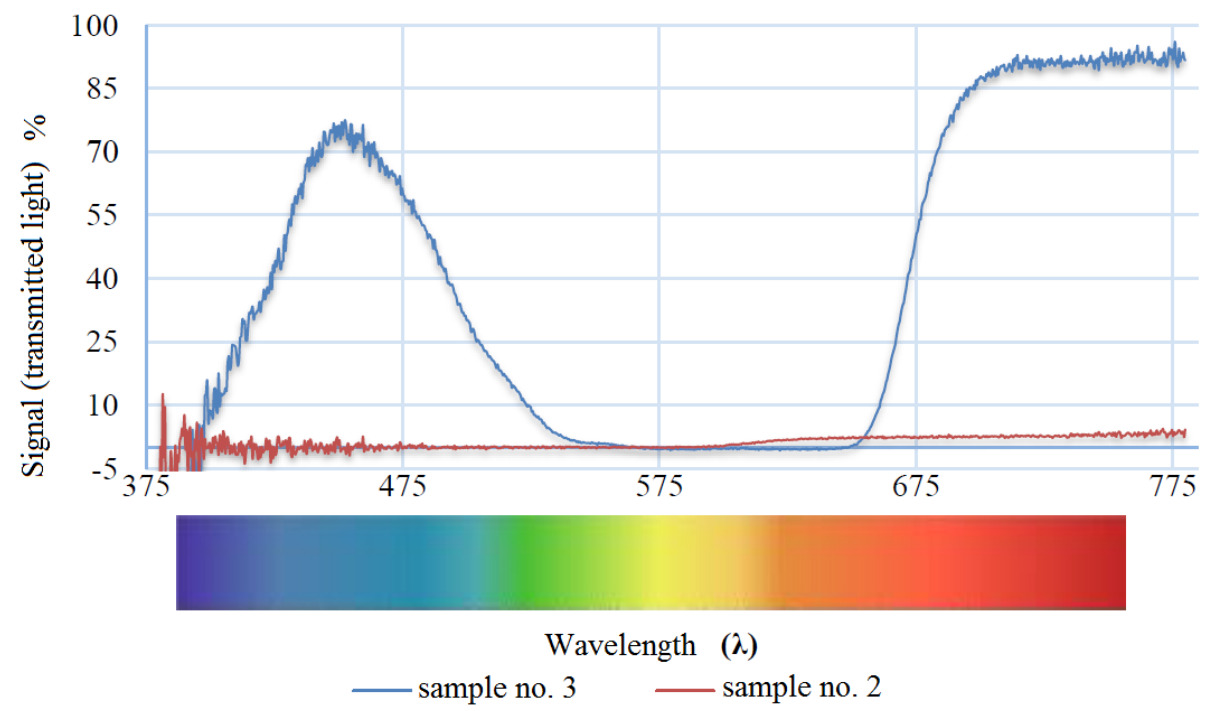

Fig. 4. Graphical representation of visible light transmission

For the experimental measurements were selected four types of samples:

- Samples no. 1 - black colour - 100\% light absorption,

- Samples no. 2. - red colour - light absorption (Fig. 4),

- Samples no. 3. - blue colour - light absorption (Fig. 4),

- Samples no. 4. - white colour - 100\% light absorption. 
Each of these samples (Fig. 3.) was subjected to a tensile strength measurement (Fig. 7.) and measurement of hardness. For the optimization of the measurements, 10 samples of each colour variation were selected.

\subsection{Measure of tensile strength}

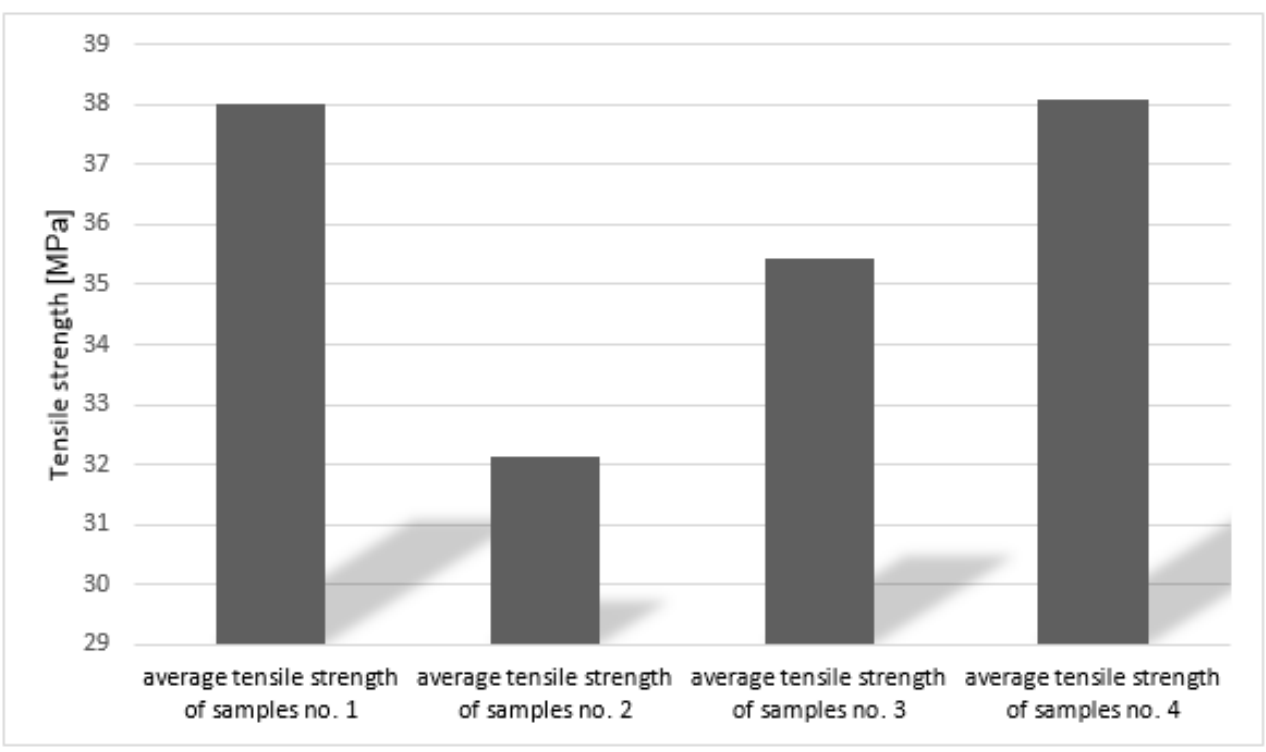

Fig. 5. The average values of tensile strength

From the measured values, it can be stated that samples with light transmission at a certain wavelength have lower tensile strengths. This fact may be attributed to the optical properties of PMMA when changing colour. Samples with 100\% light absorption (no. 1 and no. 4) have an average tensile strength of $38.01 \mathrm{MPa}$, respectively. 38.09 MPa. Samples no. 2 and 3 achieve a tensile strength of $32.13 \mathrm{MPa}$, respectively. $35.44 \mathrm{MPa}$ (Fig. 5).

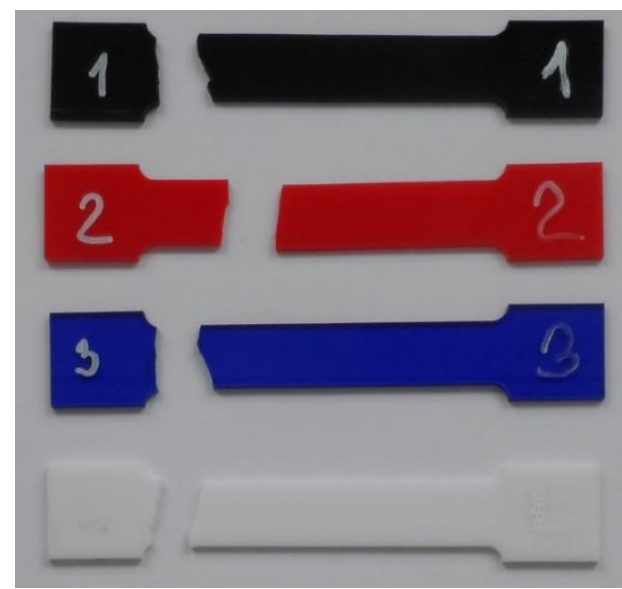

Fig. 6. Image of the used samples 


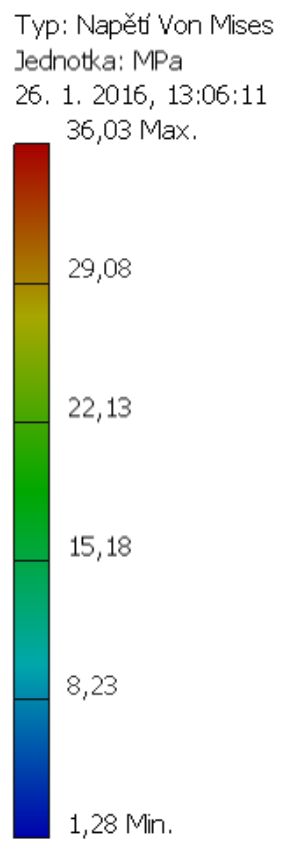

Fig. 7. Simulation tests of tensile strength

\subsection{Measure of hardness}

From the measured values, it can be conclude that samples with light transmission at a certain wavelength have higher hardness. Due to the higher hardness it is possible to verify lower tensile strength. This fact may be attributed to the optical properties of PMMA when changing colour. Samples with $100 \%$ light absorption (no. 1 and no. 4 ) have an average HB hardness of 27.6 HB, respectively $29.5 \mathrm{HB}$, which almost does not differ from the hardness of the base material. Samples no. 2 and 3 achieve a HB hardness of $32.7 \mathrm{HB}$, respectively $31.0 \mathrm{HB}$, which represents a relatively large increase over the hardness of the base material (Fig. 8). 


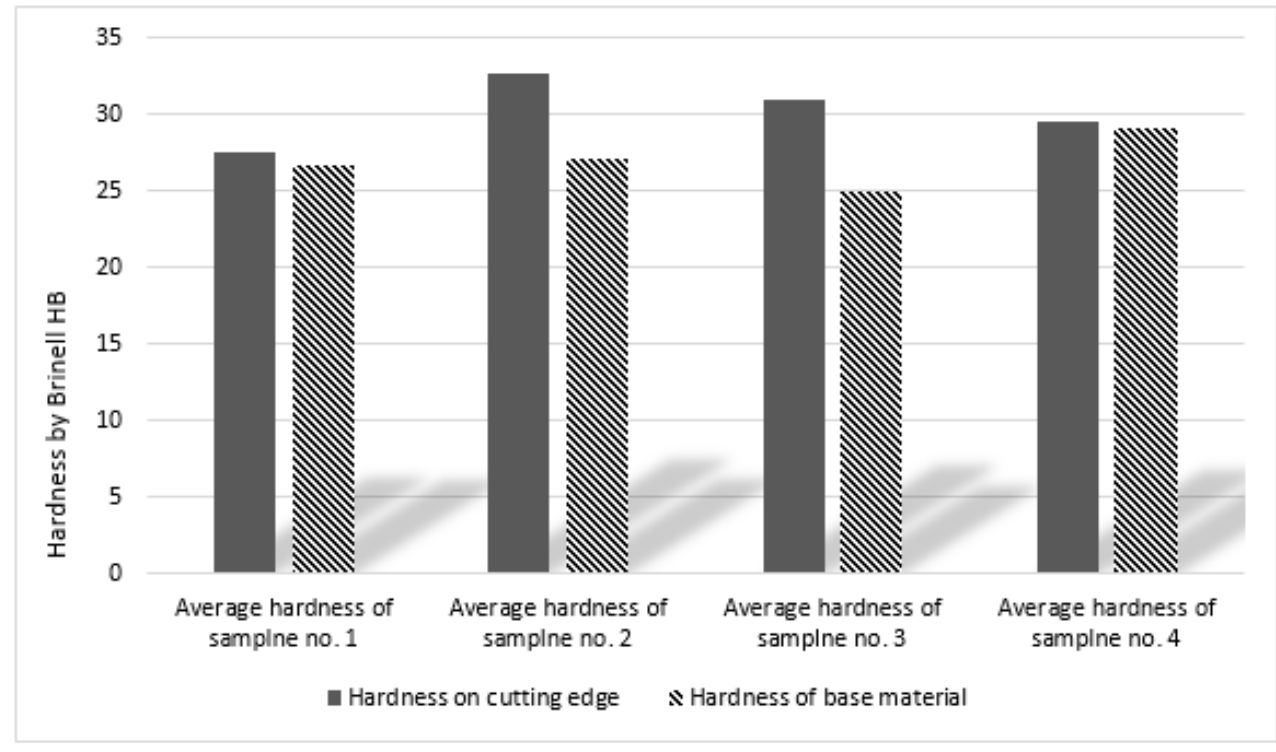

Fig. 8. The average values of hardness HB

\section{Conclusion}

The experiment unambiguously confirmed that changes in the optical properties of the same chemical composition material - PMMA, affect the mechanical properties (tensile strength and hardness) of the material after laser cutting.

In this experimental measurement were used the constant parameters of the laser cutting for each samples variant (while maintaining the dimensions and material of the samples). From the experiment it suggests that the laser cutting parameters for PMMA must be optimized for each colour option for maintaining the required mechanical properties. The concreate measurement results are presented in the experimental section of the article.

Research presented in this paper was partially financially supported through realization of projects KEGA 014ŽU-4/2016 - Responsible investigator: prof. Jozef Meško, MSc., Ph.D.

\section{References}

1. L. C. Caristan, Laser cutting guide for manufacturing. (Dearborn, Michigan, USA: Society of Manufacturing Engineers, 452 p., 2004)

2. W. T. Silvfast, Laser Fundamentals. (Cambridge University Press, 666 p., 2004)

3. J. Meško, A. Zrak, Analysis of heat transfer in laser cutting problems. Analysis of technology in various industries, Monography, Chapter 6, Częstochowa: Oficyna Wydawnicza SMJiP, (2014)

4. H. Danielewski, R. Banak, A. Domagala, The Experimental Analysis of Striation Pattern Created During Laser Cutting. Transcom 2013, Žilina, Slovakia (2013)

5. D. W. Van Krevelen, Properties of polymers. ISBN-9780080548197 (2009)

6. Y. Huang, S. Liu, W. Yang, Ch. Yu, Surface roughness analysis and improvement of PMMA-based microfluidic chip chambers by CO2 laser cutting. Applied surface science 256, 1675-1678 
7. EUROLASER [online] http://www.eurolaser.com/cz/products/laser-systems-foracrylic/xl-1200-acrylic/ (2015)

8. J. Meško, A. Zrak, K. Mulczyk, S. Tofil, Microstructure analysis of welded joints after laser welding. Manufacturing technology 14 (3), 355-359 (2014) 